\title{
An Innovative Technique to Utilize E-Plastic as Construction Material: A Review
}

\author{
Prince Singh*, Mukesh Pandey**, Sohit Agrawal*** \\ *(M.Tech Student, Department of Civil Engineering, ITM University, Gwalior-474001, India \\ ** (Professor \& Head, Department of Civil Engineering, ITM University, Gwalior-474001, India \\ *** (Assistant Professor, Department of Civil Engineering, ITM University, Gwalior-474001, India
}

\begin{abstract}
Rapid growth of technology, up gradation in latest innovation of electrical industry in $21^{\text {st }}$ century has led one of fastest growing waste stream in world commonly known as E waste. People became so techno geek that they cannot live without electronic gadget, from mobile phone to microwave, from television to telecommunication, and after their life ends, it became trash. We generate about 40 million tons of e waste every year and $30 \%$ of its part is made of plastic around 1.2 million tons of plastic and on the other side due to wide use of concrete as constructional element, accessibility of raw material is being questioned, their fore an attempt has been taken to fulfill both requirement, making concrete economical and less effective to environment. This article gives an overview of utilization of waste electronic plastic in concrete mixture as coarse aggregate. This solves the landfill problems, pollution and save economy. The use of waste material in concrete not only makes concrete economical but also helps in dumping of plastic.
\end{abstract}

Keywords: Compressive Strength, E-plastic Aggregate, Flexural Strength, Workability, Waste Management.

\section{INTRODUCTION}

Recent upgradation in field of science and technology has converted the way of living of everyone. The electronic appliance which is beyond the range of common people is now available at affordable prices. On one side where latest innovations have made life easy, on the other side it has encouraged the use and throws mind set. This mind set not only leads accumulation of billion tons of electronic products but also causes serious problem to human health and environment. According to US EPA investigation, they have estimated an increment of 5 to $10 \%$ growth in e- waste annually and only $5 \%$ is being recovered [1]. Hence, the volume of e-waste which should be disposed is increasing day by day. The composition of e-waste is comprised of iron, copper, aluminum, gold and other material which covers $60 \%$ of its composition while-plastic accounts of $30 \%$, and other hazardous pollutants covers $2.70 \%$ [1]. E-waste is define as loosely discarded computers, laptops, washing machine, radio, television refrigerator, mobile phone and other electrical products. In India, the generation of electronic waste is mostly from metropolitan cities like Delhi, Mumbai, Kolkata, Bangalore etc. Around $60 \%$ of ewaste is being generated from 65 cities in India and 10 states assists $70 \%$ of e-waste in which Maharashtra is on top rank trailed by Tamil Nadu and Andhra Pradesh. There are only two dismantling facilities like WEEE that is being processing in cities like Chennai and Bangalore [2]. Utilisation of e- plastic material as coarse aggregate in construction is one of the most efficient way of disposal of plastic that's reduces the landfill space, environmental impacts and requirement of natural raw material [3]. Hence, it is very necessary to find an innovative way for the disposal of the e-waste and using these ewastes as a partial replacement of coarse aggregate up to desired limit in concrete can be one of the many ways for the disposal of waste material.

\subsection{COMPOSITION OF E-WASTE}

- Plastic-30\%

- Refractory Oxides - 30\%

- Copper - $20 \%$

- Iron $-8 \%$

- $\operatorname{Tin}-4 \%$

- Lead $-2 \%$

- Nickel - $2 \%$

- Aluminum - 2\%

- Others $-2 \%$.

\subsection{PROPERTIES OF PLASTIC MATERIAL}

Plastic is an essential part of our society and most significant innovation of $20^{\text {th }}$ century, expansion growth in consumption leads to accumulation of plastic is noticed all over globe which increases the production of plastic related waste. It contains several toxic chemical and thus pollutes air, water, and soil. Some of it property shows that it can be used as construction material are as follows. 
*Plastics are sufficiently strong and can be used for load bearing structure. Its strength can be further improvised by reinforcing them with fibrous material.

*Plastics offer great resistance to moisture, chemicals, solvent and impact.

* Plastic has an adverse affect on air content of concrete. With increment of $0.5 \%$ plastic, air content of concrete was increased where as workability was reduced.

*Plastics are good in thermal and acoustic insulation and lighter in weight its incorporation in concrete reduces the dead weight of the structure.

\section{LITERATURE REVIEW}

Some of the previous research work on utilization of waste E-plastic in concrete is discussed briefly.

Amiya Akram, C. Sasidhar, K. Mehraj Pasha et al. 2015 [1]. Their experiment s attention is on utilization of e-plastic in concrete and their possibility of using shredded plastic as substitution of coarse aggregate. It was noticed that when only EPlastic was used in concrete mix, its strength decreases but addition of $10 \%$ fly ash in same concrete mix shows comparable strength to conventional concrete. Through this experimental study author concluded an assumption that e-plastic has viability to be utilized as construction material and hence lowers the necessity of natural coarse aggregate, resulting in preservation of coarse aggregate. In their paper, they used the e-plastic with difference of $5 \%$ by their weight with every change in coarse aggregate with 0 to $5 \%$, from 5 to $10 \%, 10$ to $15 \%$, and 15 to $20 \%$ for M20 grade. There is decrease of $18.18 \%, 24.24 \%$ and $24 \%$ with increase of every $5 \%$ at the age of 7 days curing. And after 28 days the decrease in compressive strength is $35 \%$, $37.5 \%$ and $43 \%$.

Sunil Ahirwar et al 2016 [2]. The author of this paper has used e-plastic waste with replacement of coarse aggregate. The author's main motto is to analyze the mechanical property containing e-plastic waste concrete compared to conventional concrete from o to $30 \%$ and fly ash is also added in this mix $10,20,30 \%$ by partial replacement of cement. He made a conclusion at the end that e-plastic waste can replace by coarse aggregate up to $30 \%$ when fly ash replaces cement by $30 \%$

Ashwini Manjunath B T et al 2015 [3] Author implemented an experimental study to utilize the E-plastic waste on concrete with the percentage ratio of $0 \%, 5 \%, 10 \%, 15 \%, 20 \%, 25 \%, 30 \%$ on the strength criteria of M20 grade mix. Compressive, tensile, and flexural strength was observed with and without e-plastic as aggregate which exhibit good strength. The feasibility of using e-plastic waste as coarse aggregate is presented in this study. He concluded that plastic can be used to replace some of the aggregate in concrete mixture, and this contributed in reducing the unit weight of concrete. He also concluded that introduction of plastic in concrete made concrete ductile. In this paper, author concluded that with increase of every $5 \%$ of e-plastic in concrete, decrement in compressive strength is from $8.33 \%$ to $55 \%$ for 7 days and after 28 days the decrement in strength is $6.38 \%, 46.80 \%$ and $53 \%$.

Ankit Arora and Dr. Urmil V. Dave et al 2013 [4]. The author of this article utilizes the-plastic waste originated from electronic devices and plastic bottles and conducted an experiment. The-wasteplastic is shredded in to size of $2 \mathrm{~mm}$ and replaces it with fine aggregate to act as filler in concrete with $\%$ ratio of 0,2 and $4 \%$ for M20 grade. Later on the compressive strength is noticed for 28 days. The reduction in compressive strength is noticed from $8.445 \%$ to $17.57 \%$ for e-waste concrete where on other hand the-plastic concrete reduction ranges from $5 \%$ to $12.12 \%$ for 28 days.

Bharat Dawande, Devansh Jain, Dr. Gyanendra Singh 2016 [5]. The author of this paper used e-plastic waste material and replaces with coarse aggregate up to $25 \%$ with regular interval of $5 \%$ where as cement is partially replaced with fly ash. Workability of fly ash with electronic plastic waste concrete is even more than conventional and e-plastic waste concrete. In his paper, it can be concluded that e-plastic waste could be used in concrete as coarse substitution up to $10 \%$ alone and up to $25 \%$ with fly ash. Workability of fly ash with e-plastic waste concrete has even more than conventional and eplastic waste concrete. The author recorded decrement in strength for 7 days from $1.78 \%$, to $13.05 \%$ and same for 28 days compressive strength the decrease in strength from $3.37 \%$, to $20.29 \%$.

Lakshmi R, Nagan S. et al 2010[6]. She conducted an experimental study to analyze the mechanical property of concrete incorporated with Eplastic waste for M20 grade with replacement ratio from 0 to $30 \%$. Compressive, flexural and tensile strength of concrete with and without e-plastic as aggregate is investigated, later on she added fly ash and reduction in strength is being noticed for 28 days. The decrement in compressive strength of e-plastic concrete without fly ash is recorded from $0.31 \%$ to $69.08 \%$. The strength reduction for concrete incorporated with E-plastic and fly ash is recorded from $6.54 \%$ to $24.74 \%$. She concluded at last that around $20 \%$ of e-plastic waste could be utilized in concrete as coarse aggregate with acceptable strength.

\section{Pravin A. Manatkar, Ganesh} P.Deshmukh et al 2014 [7]. Generation of e-waste in 2014 is around 6.5 lakh MT which is very serious issue and its solution is needed to be find out. In this paper, author compare the strength of two different grade mix of $\mathrm{m} 20$ and $\mathrm{m} 25$ with replacement of coarse aggregate by non metallic e-waste from 0 to 
$20 \%$. In his paper it could be seen that with every $5 \%$ of non metallic e-waste in concrete results into decrement of $1.21 \%, 22.1 \%, 27.43 \%$ and $39.02 \%$ for 7 days result. Same for 28 days the decrement will be $1.21 \%, 8.56 \%, 14.58 \%$ and $20.55 \%$. Author concluded in his paper that use of non metallic ewaste is applicable up to $5-6 \%$ in building and road construction. $10 \%$ e-plastic waste could be used for low strength construction, more than $10 \%$ is not suggested to utilize in construction for their low strength.

Suchithra et al 2015 [8]. She conducted an experiment on $\mathrm{m} 20$ grade mix. The replacement of coarse aggregate by e-plastic waste from $0 \%$ to $20 \%$ .After that mechanical and durability properties of conventional concrete specimen mix is being compared with the specimen containing e-plastic waste in it. The test result shows enhancement in compressive strength of e-plastic waste concrete compared to conventional concrete and can be effectively used in concrete. Author concluded that use of e-plastic waste up to $15 \%$ incorporation shows enhancement in compressive strength and flexural strength. She concluded that with the increase of $5 \%$, $10 \%, 15 \%, 20 \%$ e-waste their respective strength are $17.7 \mathrm{n} / \mathrm{mm}^{2}, 20.8 \mathrm{n} / \mathrm{mm}^{2}, 21.67 \mathrm{n} / \mathrm{mm}^{2}, 23.8 \mathrm{n} / \mathrm{mm}^{2}$ for 7 days continuous increase of $17.51 \%, 22.31 \%$, $25.95 \%, 30.36 \%$ and for 28 days strength is 28.6 , $31.6,33.2,35.5,25 \mathrm{n} / \mathrm{mm}^{2}$ and change in compressive strength can be noticed for every $5 \%$ there is increase of $10 \%, 16.09 \%, 24.12 \%$ after that sudden decrease in strength at $20 \%$ replacement of $26.13 \%$.

\section{CONCLUSION}

It has been seen in previous studies that illustrate the use of plastic as partial replacement of aggregate in concrete. After going through various review of different literature; we could say that eplastic has ability to be utilized as coarse aggregate in construction for some percentage.

* When E-plastic aggregate is used as substitute of coarse aggregate in concrete the decrease in compressive and flexural strength is noticed.

*Utilisation of e-plastic waste in concrete is possible but at some replacement ratio to improve its mechanical property \& can be an economical way for their disposal in environmental friendly manner.

*Introduction of e-plastic waste in concrete makes concrete ductile in nature, the ability of deformation before failure of structure. The characteristic of concrete incorporated with plastic can be used where the temperature is low or moderate.

*Electronic waste management could be done by utilizing it in concrete as well as in road construction. *The workability of concrete mix is increased by increase of e-plastic in concrete because of inability of plastic to absorb water.
*In order to get desirable strength as compare to conventional concrete, industrial by product such as fly ash and silica fumes should be used.

\section{REFERENCES}

[1] Amiya Akram, C. Sasi Dhar,and K. Mehraj Pasha, E-Waste Management by Utilization of E-Plastics in Concrete Mixture as Coarse Aggregate Replacement, International Journal of Innovative Research in Science, Engineering and Technology, 4(7), 2015, 5087-5095.

[2] Sunil Ahirwar, An Experimental Study on Concrete by using E-plastic waste as Partial Replacement for Coarse Aggregate, International Journal of Science Technology \& Engineering, 3(4), 2016, 7-13.

[3] Manjunath B.t. Ashwini, Partial Replacement of E-plastic Waste as CoarseAggregate in Concrete, Procedia Environmental Sciences, 35, 2016, 731-739.

[4] Ankit Arora, and Dr. Urmil V. dave, Utilization of E-waste and Plastic BottleWaste in Concrete" International Journal of Students Research in Technology and Management, 1(4), 2013, 398-406

[5] Bharat Dawande, Devansh Jain, and Dr. Gyanendra Singh, Utilization of E- Waste as a Partial Replacement of Coarse Aggregate in Concrete, International Journal for Scientific Research \& Development, 3(11), 2016, 6-9

[6] Lakshmi R., Nagan S., study of concrete containing E-plastic waste" International Journal of Environmental Sciences, 1(3), 2010, 270-281.

[7] Pravin A. Manatkar, Use Of Non-Metallic EWaste As A Coarse Aggregate In A Concrete, International Journal of Research in Engineering and Technology, 4(3), 2015, 242-246.

[8] Suchithra S., Manoj Kumar, and Indu V.S., Study on Replacement of Coarse Aggregate by E-Waste in Concrete, International journal of Technical Research and Application, 3(4), 2015, 266-270. 